\title{
SCHWARTZ-JAMPEL SYNDROME
}

\section{Report of five cases}

\author{
Umbertina Conti Reed', Rubens Reimão², Adriana Ávila Espíndola4, Fernando Kok², \\ Lúcio Gobbo Ferreira ${ }^{3}$, Maria Bernardete Dutra Resende3, Thelma Correia Messias, \\ Mary Souza Carvalho', Aron Diament ${ }^{1}$, Milberto Scaff ${ }^{5}$, Suely Kazue Nagahashi Marie ${ }^{1}$
}

\begin{abstract}
We describe five patients with Schwartz-Jampel syndrome (SJS) examined at the outpatient service for neuromuscular disorders at our Institution from 1996 to 1999 with the objective of emphasizing the characteristic dysmorphic phenotype of SJS and its different clinical forms. Two cases presented SJS-type 1A, two had SJS-type 1B and one manifested SJS-type 2. Two boys with 3 and 13 years of age had generalized stiffness and the characteristic facial as well as osteoarticular changes from birth. Other two boys with 11 and 7 years had less marked dysmorphic changes at birth and manifested myotonia, as a limiting factor, during the second year of age. A girl with two months of age had severe myotonia from birth leading to feeding diffuculties. In all cases the diagnosis was based on dysmorphic features, and on electromyographic changes showing continuous electrical activity of muscle fibers. All were treated with carbamazepine, $20-30 \mathrm{mg} / \mathrm{Kg}$ since diagnosis. The four boys (all with normal intelligence) improved of myotonia in daily activities, markedly in three, and moderately in one. The girl did not improve and showed global development delay: by the last follow-up (at 20 months of age) she did not sit unsupported, and had mental retardation. Carbamazepine in SJS-type 1 improves general daily performance and psychological status of the patients.
\end{abstract}

KEY WORDS: Schwartz-Jampel syndrome, myotonia, carbamazepine.

Síndrome de Schwartz-Jampel: relato de cinco casos

\begin{abstract}
RESUMO - Descrevemos cinco pacientes com a síndrome de Schwartz-Jampel (SSJ) avaliados no Ambulatório de Doenças Neuromusculares da Divisão de Neurologia do Hospital das Clínicas da Faculdade de Medicina da Universidade de São Paulo, de 1996 a 1999, com o objetivo de salientar o peculiar fenótipo dismórfico e as diferentes formas clínicas da SSJ. Dois meninos apresentavam SSJ-tipo 1A, mais branda e mais tardia, dois outros meninos apresentavam SSJ-tipo1B, de início mais precoce e dismorfismos mais limitantes, e uma menina apresentava SSJ-tipo 2, forma neonatal, com grave comprometimento, inclusive da sucção. Em todos, o diagnóstico foi baseado nos aspectos clínicos dismórficos, tanto faciais como esqueléticos, e no encontro de anormalidade eletromiográfica caracterizada como atividade elétrica contínua da fibra muscular. Todos receberam carbamazepina, em doses anticonvulsivantes de 20 a $30 \mathrm{mg} / \mathrm{Kg}$, desde a realização da eletromiografia, que foi mantida nas consultas de seguimento, após períodos variando de 15 meses a 4 anos. Os quatro meninos, todos frequentando escola, apresentaram atenuação da síndrome miotônica; esta atenuação foi acentuada em três, notando-se nítida melhora da postura anormal, e moderada em um, que refere menor limitação nas atividades da vida diária. 0 quadro da menina com SSJ-tipo 2 não se modificou e a paciente manifestou retardo global do desenvolvimento, não tendo adquirido a marcha nem a linguagem por ocasião da última avaliação aos 20 meses de idade. A boa resposta dos sintomas à carbamazepina na SSJ-tipo 1 deve ser enfatizada, pois melhora a habilidade nas atividades da vida diária e o estado emocional do paciente.
\end{abstract}

PALAVRAS-CHAVE: síndrome de Schwartz-Jampel, miotonia, carbamazepina.

Schwartz-Jampel syndrome (SJS) is a rare autosomal recessive disorder first described in $1962^{1}$, characterized by generalized myotonic myopathy, masklike face, skeletal dysplasia, contracture of joints, growth retardation and bone maturation delay. Two types have been defined by the age of manifestation of the symptoms: the severe neonatal form, sometimes called type 2, and clinically indistinguishable from the StuveWiedemann syndrome (SWS) ${ }^{2-4}$, and the classical form with late infantile or childhood manifestation ${ }^{5}$. In the

Department of Neurology, School of Medicine (FMUSP), São Paulo University, São Paulo SP, Brasil: ${ }^{1}$ Associated Professor; ${ }^{2}$ Assistant Professor; ${ }^{3} \mathrm{MD}$, Post-Graduate student; ${ }^{4} \mathrm{MD} ;{ }^{5}$ Chairman.

Received 1 October 2001, received in final form 12 April 2002. Accepted 22 April 2002.

Dra. Umbertina Conti Reed - Departamento de Neurologia (FMUSP) - Avenida Dr. Arnaldo 455/4110 - 01246-903 São Paulo SP - Brasil. FAX: 5511 3061-4036, 5511 3742-2340. E-mail: ucontireed@hcnet.usp.br 
classical form, two variants have been considered regarding severity: type $1 \mathrm{~A}$, recognized in childhood, with moderate bone dysplasia, and type $1 \mathrm{~B}$, recognizable at birth, with more pronounced bone dysplasia ${ }^{6}$. Patients reported as having either neonatal SJS or SWS syndrome presented a combination of severe, prenatal-onset neuromuscular disorder with congenital joint contractures, respiratory and feeding difficulties, tendency to hyperthermia, distinct camptomelic-metaphyseal skeletal dysplasia, radiologically represented by bowing of the long bones with internal cortical thickening and large metaphyses, postnatal short stature and frequent death in infancy that is commonly due to recurrent episodes of unexplained fever. The similarity of the clinical and radiological findings between the two syndromes is mar$\mathrm{ked}^{7,8}$ but the hypothesis that SWS and SJS-type 2 are the same disorder should be testable by molecular methods ${ }^{9}$ and is not universally accepted ${ }^{10}$.

We report five patients with SJS: two of type $1 \mathrm{~A}$, two of Type $1 \mathrm{~B}$ and one of type 2, with special attention to the clinical and physical features. The good response to carbamazepine in SJS type 1 is emphasized.

\section{CASES}

Five patients with SJS were seen at the outpatient service for neuromuscular disorders, during the period of 19961999. The patients, four boys, were 3,13,11 and 7 years old at first consultation (Cases 1,2,3,4, respectively) and a girl who was referred to us at two months of age (Case 5 ). The boys had the characteristic facial and skeletal changes from birth, but in two of them (Cases 3 and 4) the myotonia appeared, as a limiting factor, only during the second year of age. The girl had severe myotonia from birth leading to feeding difficulties. There was no familial history or consanguinity. The diagnosis was based on the dysmorphic features, and on electromyographic changes showing continuous electrical activity of muscle fibers. All were treated with carbamazepine, $20-30 \mathrm{mg} / \mathrm{Kg}$, that has been administered since the diagnosis.

Case 1. A white boy, born after uneventful pregnancy from healthy nonconsanguineous parents. From birth generalized stiffness, including facial movements was noted, as well as narrowing of palpebral fissures, low-set ears, increased pursing of the lips and restriction of mouth opening. Language and mental development were normal but the child was unable to sit and from the development of independent walking at two years had to remain in a standing position. Orthopedic operations had been performed on his hips and ankles at 2 years and the patient was followed-up to age 3 years and 5 months at an orthopedic center, being since then under our care. Our first examination showed short stature and typical facial features: blepharophimosis, micrognathia, small mouth with pur- sing of the lips and high-arched palate. Pectus carinatum and kyphosis were present, the spine was rigid and a marked as well as generalized restriction of joint mobility was noted, preventing the sitting posture. Gait was stiff with minimal knee flexion. Muscular strength and deep tendon reflexes were normal. Ocular movements were normal but facial motility was reduced. An electromyography was performed showing a typical myotonic pattern characterized by spontaneous and continuous high-frequency, low-voltage electrical discharges. Treatment with carbamazepine was initiated at age 4 years and 3 months and has produced over the following months a marked improvement of generalized stiffness and developmental progress enabling the child able to sit. From 5 years the child manifested pulmonary hypertension and underwent tracheotomy at 5 years 10 months. On March 2001, at the last follow-up, the child was 7 years 9 months old and is being treated with potassium chloride, furosemide and nifedipine in addition to carbamazepine. A mild and slow improvement of joint stiffness is still noticed with the present dose of $20 \mathrm{mg} / \mathrm{Kg} /$ day of carbamazepine.

Case 2. A white boy was born after uneventful pregnancy from healthy nonconsanguineous parents. His mother reported decreased fetal activity and limb mobility. Cleft palate was noted at birth. During the first two years he underwent two surgical procedures for cleft palate correction. Motor development was delayed (he sat at 2 years and walked at 2 years and 7 months) with otherwise normal language and cognitive development. During childhood he kept an abnormal gait with hyperextended knees and bowed legs. He was first examined at our institution at age 13 years. He had short height and low weight for age, bowed limbs, marked lumbar lordosis and umbilical hernia. An unusual face was noted characterized by blepharophimosis, small mouth, microretrognathia, dental malalignment and surgically corrected cleft palate. Arms and legs mobility was decreased, there were mild bilateral ankle joint contractures and he walked with minimal flexion of knees. Muscular strength and deep tendon reflexes were decreased. Cranial nerves examination was normal. An electromyogram disclosed generalized myotonic discharges. Carbamazepine was begun and maintained at $20 \mathrm{mg} /$ $\mathrm{kg} /$ day. There was improvement in the overall mobility, the boy can remain seated more comfortably, is able to flex joints and to walk with increased speed. At the last follow-up, at 15 years he is attending high school and seems more optimistic.

Case 3. A white boy was born after uneventful pregnancy from healthy nonconsanguineous parents. At birth the mother noted that the legs were bowed, but as the child developed normally and walked independently at 17 months, she did not look for medical assistance. At 2 years she realized that the boy has a strange facial appearance characterized by narrowing of palpebral fissures and microretrognathia. From 7 years generalized increase of 
muscle tone and decrease of limb mobility were recorded. From 10 years the boy complained of pain in his legs, that worsened with repeated movements. He was examined by us at 11 years, already taking a daily dose of $200 \mathrm{mg}$ of carbamazepine. He was intelligent, attending normal school and had abnormal facial features characterized by blepharophimosis, microretrognathia, pursing of lips, abnormal dental development. His gait was stiff with flexion contractures at knees and muscle tone was increased in the lower limbs. Passive joint mobility in the upper limbs disclosed bilateral elbow contractures and in the lower limbs there was marked reduction of knee mobility and mild reduction of ankle mobility. He was noted to have a reduction of muscle mass in distal lower limbs and the remainder of his neurological examination was normal. The electromyogram revealed a generalized myotonic pattern and carbamazepine was gradually increased until 900 $\mathrm{mg}$. A slow but continuous improvement of overall activity and stiffness was reported and at the last follow-up at 13 years the boy's posture for standing up and walking was more erect and pain had disappeared.

Case 4. A black boy, was born in Luanda/Angola, after uneventful pregnancy from healthy nonconsanguineous parents. His mental and motor development were normal and he acquired independent walking at 14 months. From that time and over the next months, the mother noted a slowly progressive development of chest and spine deformities, as well as bilateral bowing of legs and knee flexion, that produced a peculiar gait. Examined at a medical service in Angola, he had muscular biopsy and electromyogram performed, and was diagnosed as SWS. During this period the child manifested malaria, receiving specific therapy. The child was first examined by us at 7 years: short stature for age, blepharophimosis, low-set ears, micrognathia, kyphoscoliosis and bowed legs were noted. He walked with both knees flexed and showed a disseminated stiffness with decreased limb and facial motility. He was noted to have muscle hypertrophy in proximal limbs and generalized contractures in the large joints. The remainder of his neurological examination was normal. Electromyography showed myotonic discharges. Carbamazepine was started in an initial dose of $10 \mathrm{mg} / \mathrm{kg} /$ day, slowly increased to $25 \mathrm{mg} / \mathrm{kg} /$ day. The child remained in Brazil for 11 months (March 2000) showing a mild improvement of limb stiffness, mainly in the elbows.

Case 5. A girl, was born after uneventful pregnancy from healthy nonconsanguineous parents. From birth limb and spine deformities were noted and the child was referred to us at three months of age. Her physical examination showed a peculiar face with blepharophimosis and pursing of the lips, kyphoscoliosis, and flexion of feet and hips. Motor and social development were delayed: the child had no head support, did not smile and did not follow objects with her gaze. There was a generalized stiffness and decreased limb mobility. An electromyogram disclosed continuous electrical activity and carbamazepine was started at a daily dose of $10 \mathrm{mg} / \mathrm{Kg}$, slowly increased. The child was referred for intensive physiotherapy and from 9 months showed a very mild improvement of general stiffness, began to smile and to direct the hands toward objects. Pursuit gaze was still intermittently impaired and in a general way the treatment was considered ineffective. At 16 months, L-dopa was started and carbamazepine was maintained, but four months later (May 2000) it was not possible to see any improvement. From that time the family abandoned follow-up.

\section{DISCUSSION}

All our patients presented with blepharophimosis, microstomia, and short stature, so composing a characteristic phenotype (Fig 1). We considered that Cases 1 and 2, who were more severely affected from birth, corresponded to SJS-type1B, according to Giedion et al. ${ }^{6}$, while Cases 3 and 4 , with less limiting and lately manifested stiffness, may represent the SJS-type1A. Case 5, whose feeding and respiratory disturbances, osteoarticular deformities, stiffness and developmental delay were very severe, probably had SJS-type 2, not yet genetically distinct from SWS. The great similarity between SJS2 and SWS points to a single entity ${ }^{3}$, an hypothesis supported by the occurrence of progressive bone dysplasia in patients with SJS type 2 or with SWS who survive beyond infancy?.

Linkage of SJS to human chromosome 1p34-p36 has been shown in families of different ethnic backgrounds where probands presented during infancy or early childhood ${ }^{11-13}$. Missense as well as splicing mutations of the gene encoding perlecan were described in three SJS1 families ${ }^{14}$. Perlecan is a large heparan sulfate proteoglycan, that is found in the basement membrane of the extracellular matrix and that is essential in maintaining cartilage integrity and in regulating muscle excitability ${ }^{14}$. However, in well documented families with severe neonatal SJS studied with microsatellite markers, no demonstrable linkage to chromosome 1 was found, suggesting that a second locus is responsible for the severe form of neonatal SJS ${ }^{15}$. In cases of SWS, cytogenetic analysis have identified mosaicism for a supernumerary marker chromosome that was shown to be derived from chromosome 5 and to contain euchromatin ${ }^{16}$. The significance of this finding for the etiology of SWS and possibly to the correlated SJS-type 2 is unknown. The genetic heterogeneity of the SJS can also be supported by the occurrence of sporadic reports of dominant autosomal inheritance ${ }^{17}$. Recently, five new mutations in the perlecan gene (HSPG2) resulting in various forms of perlecan secreted to the extracellular 
matrix in reduced levels and that are likely partially functional were identified in unrelated patients with $\mathrm{SJS}^{18}$. These findings strongly suggest that perlecan has an important role in neuromuscular function and cartilage formation ${ }^{18}$. Only further advances in molecular diagnosis will indicate whether SWS and SJS type 2 are the same disorder and will allow an effective classification of all the subtypes of SJS. In the lack of familiar cases for linkage or for other genetic molecular analysis, or when molecular studies are not available as in our cases, the electromyographic finding of continuous muscle fiber activity is the best method for diagnosis. The cause of myotonia in SJS and the way by which the altered perlecan influences the channel conductance is not clearly understood. Myotonia was attributed to a $\mathrm{Na}+$ channel defect that could induce delayed, synchronized openings of $\mathrm{Na}+$ channels, occurring even after the surface membrane repolarized. These altered membrane conductances would be responsible for the hyperexcitability and the associated slowed relaxation ${ }^{19}$.

The prevalence of mental retardation among patients with SJS has been estimated at $25 \%$, however, no mechanismhas been described. Poor language development and attention deficit disorder are also common $^{20}$. Such findings could be attributed to recurrent episodes of hypoxia and, although not clinically recognized, they could be the cause of mental retardation in Case 5. There are reports of polysomnography demonstrating obstructive sleep apnea controlled by the institution of home therapy with bi-level positive airway pressure during the night ${ }^{21}$ and we intend to propose this investigative method to the parents of Case1. Another palliative treatment procedure is the levator aponeurosis surgery for elevating the upper eyelid margin and improving the facial appearance and the self image of the patient ${ }^{22}$.

There are few therapeutic resources for improving the myotonia in SJS. Procainamide, which blocks sodium channels in muscle, and normalizes chloride conductance, inhibits the discharges as it does in other types of myotonia. Mexiletine that improves chloride conductance, phenytoin, diazepam and barbiturates were also utilized without results. Carbamazepine improves clinical myotonia, blepharospasm, general motor performance and posture. Long term therapy is necessary but adverse effects are few. Carbamazepine may be the drug of choice in the SJS, as could be demonstrated in our Cases 1 to 4 , and as has been already emphasized ${ }^{23}$.

Cases 1 to 4 manifested improvement of myotonia and of performance for daily activities, that was

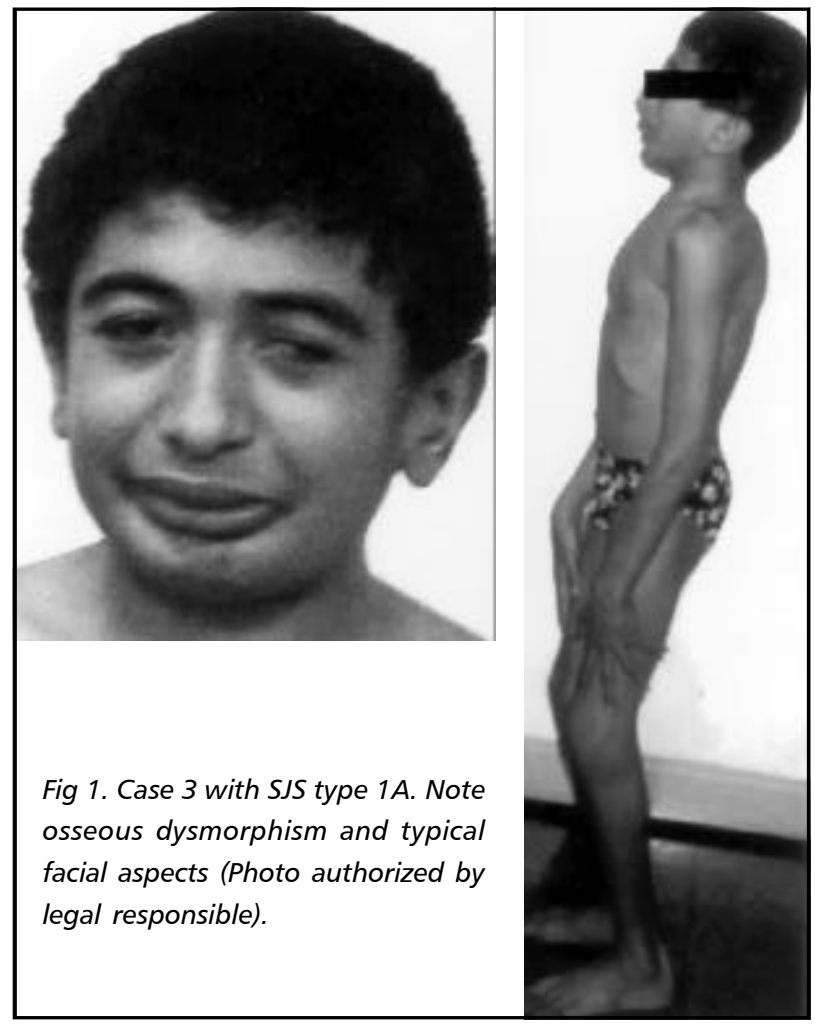

marked in three, and moderate in one. Unfortunately, in our patients the drug was not initiated at early age, in order to prevent the development of osteoarticular dysplasia of SJS, as suggested by Squires \& Prangley ${ }^{24}$.

Case 5 did not manifest any improvement and during evolution showed global development delay: by the last follow-up (at 20 months) she did not sit unsupported, and had mental retardation. This patient with the neonatal form of SJS illustrates the bad prognosis and lack of therapeutic response to carbamazepine. However, this medication should be employed for the other forms. The risk of malignant hyperthermia should be always remembered, mainly considering the high probability of a surgical procedure for minimizing blepharospasm or joint deformities.

\section{REFERENCES}

1. Schwartz O, Jampel RS. Congenital blepharophimosis associated with an unique generalized myopathy. Arch Ophthalmol 1962;68:52-57.

2. Cormier-Daire V, Munnich A, Lyonnet S, et al. Presentation of six cases of Stuve-Wiedemann syndrome. Pediatr Radiol 1998; 28:776-780.

3. Cormier-Daire V, Superti-Furga A, Munnich A, et al. Clinical homogeneity of the Stuve-Wiedemann syndrome and overlap with the Schwartz-Jampel syndrome type 2. Am J Med Genet 1998;30;78:146-149.

4. Wiedemann HR, Stuve A. Stuve-Wiedemann syndrome: update and historical footnote. Am J Med Genet 1996;63:12-16.

5. Al-Gazali LI, Varghese M, Varady E, Al Talabani J, Scorer J, Bakalinova D. Neonatal Schwartz-Jampel syndrome: a common autosomal recessive syndrome in the United Arab Emirates. J Med Genet 1996;33:203-211.

6. Giedion A, Boltshauser E, Briner J, et al. A. Heterogeneity in SchwartzJampel chondrodystrophic myotonia. Eur J Pediatr 1997;156:214-223. 
7. Christova LG, Alexandrov AS, Ishpekova BA. Single motor unit activity pattern in patients with Schwartz-Jampel syndrome. J Neurol Neurosurg Psychiatry 1999;66:252-253.

8. Sigaudy S, Moncla A, Fredouille C, Bourliere B, Lambert JC, Philip N. Congenital bowing of the long bones in two fetuses presenting features of Stuve-Wiedemann syndrome and Schwartz-Jampel syndrome type 2. Clin Dysmorphol 1998;7:257-262.

9. Superti-Furga A, Tenconi R, Clementi M, et al. Schwartz-Jampel syndrome type 2 and Stuve-Wiedemann syndrome: a case for "lumping". Am J Med Genet 1998;78:150-154.

10. Spranger J, Hall BD, Hane B, Srivastava A, Stevenson RE. Spectrum of Schwartz-Jampel syndrome includes micromelic chondrodysplasia, kyphomelic dysplasia, and Burton disease. Am J Med Genet 2000;94:287-295.

11. Nicole S, White PS, Topaloglu H, et al. The human CDC42 gene: genomic organization, evidence for the existence of a putative pseudogene and exclusion as a SJS1 candidate gene. Hum Genet 1999;105:98-103.

12. Nicole S, Ben Hamida C, Beighton P, et al. Localization of the SchwartzJampel syndrome (SJS) locus to chromosome 1p34-p36.1 by homozygosity mapping. Hum Mol Genet 1995;4:1633-1636.

13. Fontaine B, Nicole S, Topaloglu H, et al. Recessive Schwartz-Jampel syndrome (SJS): confirmation of linkage to chromosome $1 \mathrm{p}$, evidence of genetic homogeneity and reduction of the SJS locus to a 3-cM interval. Hum Genet 1996;98:380-385.

14. Nicole S, Davoine CS, Topaloglu H, et al. Perlecan, the major proteoglycan of basement membranes, is altered in patients with Schwartz-Jampel syndrome (chondrodystrophic myotonia). Nat Genet 2000;26:480-483.

15. Brown KA, al-Gazali LI, Moynihan LM, Lench NJ, Markham AF,
Mueller RF. Genetic heterogeneity in Schwartz-Jampel syndrome: two families with neonatal Schwartz-Jampel syndrome do not map to human chromosome 1p34-p36.1. J Med Genet 1997;34:685-687.

16. Chen E, Cotter PD, Cohen RA, Lachman RS. Characterization of a long-term survivor with Stuve-Wiedemann syndrome and mosaicism of a supernumerary marker chromosome. Am J Med Genet 2001;101:240-245.

17. Spaans F. Schwartz-Jampel syndrome with dominant inheritance. Muscle Nerve 1991;14:1142-1144.

18. Arikawa-Hirasawa E, Le AH, Nishino I, Nonaka I, et al. Structural and functional mutations of the perlecan gene cause Schwartz-Jampel syndrome, with myotonic myopathy and chondrodysplasia. Am J Hum Genet 2002; 70: 1368-1375.

19. Lehmann-Horn F, Iaizzo PA, Franke C, Hatt H, Spaans F. SchwartzJampel syndrome:II. Na+ channel defect causes myotonia. Muscle Nerve 1990;13:528-535.

20. Paradis CM, Gironda F, Bennett M. Cognitive impairment in SchwartzJampel syndrome: a case study. Brain Lang 1997;56:301-305.

21. Cook SP, Borkowski WJ. Obstructive sleep apnea in Schwartz-Jampel syndrome. Arch Otolaryngol Head Neck Surg 1997;123:1348-1350.

22. Cruz AA, Souza CA, Plastino LSJr. Levator aponeurosis surgery in SchwartzJampel syndrome. Ophthal Plast Reconstr Surg 1998;14:271-276.

23. Topaloglu H, Serdaroglu A, Okan M, Gucuyener K, Topcu M. Improvement of myotonia with carbamazepine in three cases with the Schwartz-Jampel syndrome. Neuropediatrics 1993;24:232-234.

24. Squires LA, Prangley J. Neonatal diagnosis of Schwartz-Jampel syndrome with dramatic response to carbamazepine. Pediatr Neurol 1996;15:172-174. 